\title{
An investigation into the cardiometabolic risk amongst young adults from different ethnic backgrounds
}

\author{
D. O’Hagan, I. Alaunyte and F. Amirabdollahian \\ School of Health Sciences, Liverpool Hope University, Liverpool, L16 9JD
}

Cardiometabolic risk can be characterised by identifying the existence of the components of the metabolic syndrome, namely through studying measures of central obesity, impaired glucose metabolism, hypertension and dyslipidaemia ${ }^{(1)}$. Previous studies reported higher prevalence of the individual elements of this risk among minority ethnic groups; for instance demonstrating that the prevalence of doctor diagnosed diabetes (markedly increasing with age) was three to five times higher among Black Asian Ethnic Minority (BAME) groups particularly of Bangladeshi, Pakistani, Indian and Black Caribbean origin in comparison with general public; or highlighting that Irish men had the highest prevalence of the any cardiovascular disease, compared with other minority ethnic groups and/or general population ${ }^{(2)}$; however, studies on ethnic difference in collective cardiometabolic risk profile of young adults have been scarce. The aim of this study was to investigate ethnic difference in the cardiometabolic risk factors amongst young adults residing in North West of England.

After obtaining ethical approval, participants (n 238) aged 18-24 were recruited in a cross-sectional study. Laboratory and anthropometric measures of cardiometabolic risk were assessed including blood pressure, measures of central obesity and biomarkers of fasting capillary blood glucose and lipid profile. Energy and macronutrient intake was measured using a validated 3-day diet diary and analysed using dietary assessment software Microdiet. Normal distribution was investigated using the Shapiro-Wilk test of normality and because the main variables were not normally distributed $(\mathrm{P}<0.05)$, variation in risk factors was investigated using the nonparametric Kruskal-Wallis Test. Statistical analysis were conducted using SPSS 22 and statistical significance was set at 0.05 .

Despite detailed analysis of blood pressure, anthropometric, dietary and laboratory measures of the cardiometabolic risk including weight, BMI, percentage body fat, waist circumference, weight to hip ratio, energy and macronutrient intake, dietary total, saturated and unsaturated fatty acid intake, physical activity and exercise, there were very few significant variation associated with the ethnicity. The only statistically significant variations are shown in table 1.

Table 1: Ethnic variation in cardiometabolic risk profile of young adults. In columns, medians that have no superscript in common are significantly different from each other $(\mathrm{P}<0 \cdot 05)$.

\begin{tabular}{|c|c|c|c|c|c|}
\hline & & $\begin{array}{l}\text { Whole Blood Total } \\
\text { HDL }(\mathrm{mmol} / \mathrm{L})\end{array}$ & $\begin{array}{l}\text { Whole Blood Total } \\
\text { LDL }(\mathrm{mmol} / \mathrm{L})\end{array}$ & $\begin{array}{l}\text { Whole Blood Ratio } \\
\text { of Total Cholesterol } \\
\text { to HDL }\end{array}$ & $\begin{array}{l}\text { Whole Blood } \\
\text { Glucose } \\
\text { Concentration } \\
(\mathrm{mmol} / \mathrm{L})\end{array}$ \\
\hline \multirow{6}{*}{$\begin{array}{l}\text { White Caucasian } \\
\text { (excluding Irish) } \\
N=179 \\
\text { Irish } N=45\end{array}$} & Median & $1 \cdot 30^{\mathrm{a}}$ & $2 \cdot 23^{\mathrm{a}}$ & $3 \cdot 1^{\mathrm{a}}$ & $4 \cdot 78^{a}$ \\
\hline & $\mathrm{P} 25$ & 1.08 & 1.77 & $2 \cdot 6$ & $4 \cdot 53$ \\
\hline & P75 & $1 \cdot 55$ & $2 \cdot 68$ & $3 \cdot 7$ & $5 \cdot 13$ \\
\hline & Median & $1 \cdot 30^{\mathrm{a}}$ & $1.85^{b}$ & $2 \cdot 7^{\mathrm{b}}$ & $5.04^{b}$ \\
\hline & $\mathrm{P} 25$ & $1 \cdot 18$ & 1.57 & $2 \cdot 4$ & 4.58 \\
\hline & P75 & $1 \cdot 58$ & $2 \cdot 21$ & $3 \cdot 5$ & $5 \cdot 57$ \\
\hline \multirow[t]{3}{*}{ BAME $N=7$} & Median & $1.82^{b}$ & $2 \cdot 08^{a b}$ & $2 \cdot 3^{b}$ & $4.63^{\mathrm{ab}}$ \\
\hline & $\mathrm{P} 25$ & $1 \cdot 58$ & 1.56 & $2 \cdot 2$ & $4 \cdot 19$ \\
\hline & P75 & $2 \cdot 19$ & 2.94 & $3 \cdot 1$ & $5 \cdot 20$ \\
\hline Other ethnic & Median & $1 \cdot 40^{\mathrm{a}}$ & $2 \cdot 20^{\mathrm{ab}}$ & $2 \cdot 8^{\mathrm{ab}}$ & $4 \cdot 50^{a b}$ \\
\hline \multirow{2}{*}{ background $\mathrm{N}=7$} & $\mathrm{P} 25$ & $1 \cdot 33$ & 1.81 & $2 \cdot 5$ & $4 \cdot 38$ \\
\hline & P75 & $1 \cdot 50$ & $2 \cdot 73$ & 3.9 & 4.74 \\
\hline
\end{tabular}

Despite significantly higher whole blood HDL of BAME compared with other groups and in spite of a significant variation in whole blood LDL, ratio of total cholesterol to HDL and whole blood glucose concentration based on ethnicity, the median level of biomarkers for all ethnic groups were within the normal range. Overall, the current study did not confirm the previously reported extensive variations in cardiometabolic risk between ethnic groups. The observed variations in biomarkers warrant further investigation with larger sample sizes and better representation of all minority ethnic groups residing in the UK.

1. van Vliet M, von Rosenstiel I, Schindhelm RK, et al. (2009) Cardiovasc Diabetol, 8:2

2. Health Survey for England (2004) Health of Ethnic Minorities, Main report. The information Centre. 